\title{
Two Wheels and Rationality?
}

Ying Ying Ooi \& Chandrashekar Venkataraman

Robert M. Pirsig (1974), in his book Zen and the Art of Motorcycle Maintenance, writes "I feel some anxiety about this, which I realize is irrational and try to get rid of by talking about the road. There's no way to fall off. No danger to the motorcycle. Just a memory of places where you could throw a stone and it would drop thousands of feet before coming to a rest and somehow associating that stone with the (motor)cycle and rider."

The notion of motorcycle riding, or more commonly, motorcycling, being irrational is not new; we would venture that not much has changed in over a century since its invention as far as it being intrinsically irrational is concerned. It was seemingly irrational to Pirsig when he was riding way back in the 50s and 60s, and continues to be irrational even today. We can reaffirm this view based on our personal experiences as motorcycle rider and pillion. However, the economists in us seek a rational explanation to the act of motorcycling, and we explore that perspective in this paper.

Arguably, and for the ease of exposition, we separate all motorcyclists into two groups. Group A consists of those who use a motorcycle as their sole mode of transport and commute using a motorcycle (we further subdivide this group into Groups A1 and A2) and Group B consists of those who use a motorcycle for leisure or recreation (again further subdivided into Groups B1 and B2). Both groups of motorcyclists have their rational reasons for motorcycling. Both find their own reasons rational, and those of the other kind irrational, primarily because of their differing usage of a motorcycle. To society, or at least the society of nonmotorcyclists, however, both kinds of motorcyclists appear to be irrational. 
Rationality relates to the idea of reason. It involves decision making based on some form of logic. However, as such, rationality must also appeal to a collective or shared socio-economic understanding which may not always agree with logic or reason as defined by the individual. This cultural or socio-economic aspect of how rationality is defined also plays an important role in determining how something may be classified as rational by one individual and irrational by another.

Consider the idea of affordability. The affordability of any item is a combination of factors such as wealth and opportunity cost. Opportunity cost is the cost incurred as a result of an alternative forgone. It encapsulates both purchasing cost and economic benefit (utility) which was not incurred as a result of the decision made. The opportunity cost of a given form of transport is considered to be high when the utility that would have accrued from an alternative form of transport is higher. A lower opportunity cost would thus be incurred by those individuals who are unable to afford alternative means of transport, such as an automobile, or for those who cannot manage with public transport.

Alternatively, the opportunity cost of owning a motorcycle would be considered to be high when the utility incurred from its use in travel, for investment, or pleasure is comparatively lower. A higher opportunity cost would, thus, be incurred by those individuals who are able to afford alternative means of transport but purchase motorcycles instead. Unless we make the assumption that these individuals are able to afford much more, their opportunity cost of owning a motorcycle is high.

To examine opportunity cost thoroughly, the utility of the motorcycle has to be considered. Utility is a measure of relative satisfaction from the consumption of various goods and services. A utility function allows us to examine the measure of relative satisfaction succinctly and in mathematical terms. We can write a generic utility function for a motorcycle rider as

$\mathrm{U}$ (motorcycle rider $)=\mathrm{f}($ commuting, travel, sport, enjoyment $)$. 
In the above equation, sport or enjoyment would involve the highest level of risk, and is therefore more likely to be considered irrational by the social determination of what constitutes rational behaviour.

The socio-economic aspects of owning a motorcycle can be examined using Maslow's Hierarchy of Needs. Abraham Maslow divides the factors which motivate people into five categories: Physiological needs, Safety needs, Belonging needs, Esteem needs, and Self-Actualization (Ivancevich, Olekalns \& Matteson 2007). These levels of needs exist in a hierarchical structure from physiological needs to selfactualization. Thus, the first need must be met and satisfied before the next one can be felt by an individual.

With opportunity cost and utility defined in terms of economic factors, and Maslow's hierarchy in place for unraveling socio-economic factors, we can now reexamine the two groups of motorcyclists: commuters (Group A1 and Group A2) and recreational users (Group B1 and Group B2).

Group A predominantly consists of those who use motorcycles for commuting. This group is further subdivided into Group A1, those who commute by motorcycle out of necessity and Group A2, those who choose to commute using a motorcycle. Group A1 consists of those individuals who use a motorcycle to commute daily. The opportunity cost associated with owning a motorcycle is low among Group A1. The main reason being that they have no other means of commuting apart from a motorcycle anyway, and this affects the kind of motorcycles they purchase. Often the motorcycles they purchase will be practical, multi-purpose vehicles, capable of both city traffic and long-distance travel. Thus, Group A1 looks for an inexpensive alternative to public transport or perhaps a very cheap used car - the only alternatives if the motorcycle was taken away. Affordability and reliability will be the major criteria here. This group looks the most rational when it comes to 
motorcycling mainly because the utility they derive from it originates from of a need rather than a want. In a way, the motorcycle enables their sustenance. Members of Group A2 use motorcycles not because they cannot afford an automobile, but because they save time by riding a motorcycle that can maneuver quickly through traffic and is easier to park. To these individuals the opportunity cost of time spent on commuting, or in other words, their time cost of money, is very high. Although these individuals may well have expensive automobiles at home, they nonetheless commute using motorcycles because they save time doing so. They save time in traffic and also in finding parking. It is time, rather than affordability, that is a constraint for this group. Various members of society would consider this group to be highly irrational mainly because they choose to ride a cheap and potentially unsafe form of transportation such as a motorcycle while possessing automobiles or even chauffeurs.

As far as Maslow's hierarchy is concerned both Group A1 and Group A2 fall under the level of Safety needs. The only difference between Group A1 and Group A2 is that Group A1 commutes by motorcycle because they have no alternative and Group A2 commutes by motorcycle in order to save time. The operative word here is 'commute'. Group A2 will happily shift to driving a luxurious car when time is available to them but need a motorcycle to commute. Group A1 will still travel by motorcycle whether time is at a premium or not.

Group B1 on the other hand uses motorcycles purely for recreational purposes rather than commuting. The opportunity cost associated with owning a motorcycle is very low for this group as well as there are no alternative modes of transportation available to this group that would give them as much utility as a bike does even if they are far more valuable. A keen eye will be able to pick up these motorcyclists as having the most impractical and flashiest of motorcycles - fast machines which would be stuck in second gear all day in the city, or machines with so much chrome and such high engine capacities that they make a hot-rod look relatively 
inexpensive. Often these motorcycles will be purpose built vehicles - built either for speed, or adventure, or pure viewing pleasure.

Group B2 uses motorcycles because they want to make a statement about something. Group B2 has other modes of transport available, often more preferable to riding a motorcycle, thus increasing the opportunity cost associated with owning a motorcycle. Nevertheless, Group B2 chooses to ride a motorcycle because they are aiming for a 'belonging' need. Group B2 also chooses to ride because they are pursuing a cause. Most often this cause is a social cause, such as reducing pollution and saving the environment or reducing congestion, which, according to them, is highly rational.

Groups A2 and B1 pertain to the Self-actualization needs level in Maslow's hierarchy of needs. These groups pursue the ownership of a motorcycle either as a hobby or a means to achieve a higher end. Self-actualizing, also interpreted as selffulfillment, is a focus on self. Thus, both these groups ride motorcycles for reasons other than commuting. Group B2 falls into the 'belonging' needs level in Maslow's hierarchy because they feel the need to belong to the 'right side' of society. These individuals strive to belong to a group, such as environmentalists, and thus take to riding in order to make a statement.

Motorcycle riders ride for various reasons. These reasons are weighed by the riders themselves and members of society in order to develop individual and collective opinions respectively. This drives a wedge between individual and social definitions of logic and reason and gives rise to the potential for an externality. An externality is a situation that creates a positive or negative impact on a given entity not directly involved in a decision or activity. The motorcyclists' decision to stick to their riding can have either positive or negative externalities depending on whether the act of riding translates into a cost or a benefit. A positive externality, or benefit, would include the saving of fuel because on average motorcycles consume lesser fuel than 
automobiles to cover the same distance. Other positive externalities would be lesser pollution, lower emissions from smaller engines, lesser congestion on the streets, and more parking spaces available in the city. All these reasons that create positive externalities make motorcycling more rational from the perspective of society.

However, one of the largest negative externalities, or cost, from motorcycle riding would have to be the burden on the public healthcare system when accidents involving a motorcycle occur. This is because the rider and pillion are exposed to the elements to a much higher degree than those traveling by an automobile or public transport. In the event of an accident, the injuries suffered by the motorcyclists are often more severe. According to VicRoads, motorcyclists comprise $1 \%$ of road traffic volume, but account for $14 \%$ of road fatalities and serious injuries (Brennan \& Beer 2007). An increased accident rate would further lead to increased costs because of a collective rise in the insurance costs of all road users. Since the cost is to the whole of society, society calls for a reduction of motorcycle riders on the road, claiming that these negative externalities are evidence of it being an irrational pursuit. The following table shows a summary of the road deaths involving motorcyclists in Australia.

\section{TABLE 1: SUMMARY OF ROAD DEATHS BY ROAD USER GROUP AND CRASH TYPE}

$\begin{array}{lcccccccc} & 1999 & 2000 & 2001 & 2002 & 2003 & 2004 & 2005 & \begin{array}{c}\text { Change: last two } \\ \text { years relative to } \\ \text { first two }\end{array} \\ \begin{array}{l}\text { Motorcyclist: } \\ \text { single-vehicle crash }\end{array} & 66 & 80 & 89 & 101 & 61 & 81 & 94 & +20 \% \\ \begin{array}{l}\text { Motorcyclist: } \\ \text { multi-vehicle crash }\end{array} & 110 & 111 & 127 & 123 & 127 & 115 & 139 & +15 \% \\ \text { All road users } & 1764 & 1817 & 1737 & 1715 & 1621 & 1598 & 1635 & -10 \%\end{array}$

Adapted from VicRoads' National Road Safety Action Plan 2007 \& 2008, 2007 
In economics, where all decisions are considered to be made by rational individuals, the decision to ride a motorcycle would be considered rational by those who ride. However, as we have seen, society may consider it highly irrational when it weighs the negative externalities motorcycling riding imposes compared to the positive ones it provides, especially for those riders who have alternatives available at their disposal (Groups A2, B1 and B2).

The government tries to rationalize motorcycling by intervening in the market of motorcyclists and making license requirements stringent and imposing regulations on the purchase of motorcycles by riders, both novice and experienced.

Government also provides ongoing support by educating other road users to be more aware of riders and asking riders themselves to be more aware of the potential dangers they encounter on the road. Private motorcycle manufacturers answer the call for higher safety with innovation. In order to make motorcycles safer, manufacturers have started innovating with three-wheeled motorcycles in the hope that these vehicles will prove to be safer and more stable while still maintaining the utility functions of enjoyment and travel. The new Spyder Roadster by Bombardier Recreational Products and the MP $3^{\circ}$ Scooter by Piaggio are such vehicles - safer but with the same amount of enjoyment. Similarly, BMWs two-wheeler $\mathrm{C}^{\circ}$ radically changed the way motorcyclists ride - without the need for helmets.

In making motorcycles safer some manufacturers have inadvertently opened up a new market by reducing the cost of motorcycling. This new market includes those who previously found motorcycling too irrational and were relying on either automobiles or the public transport network. Naturally, this market includes some individuals from that part of society which previously bore much of the negative externalities associated with motorcycling. So perhaps the reduction in the overall cost of motorcycling, with better technology, may prove to be a means by which 
society will find it easier to rationalize the act of motorcycling, making it more acceptable.

Given the risks involved, how safe, and thus rational, is it really to ride a motorcycle? The question boils down to one of discounting - how much is an individual willing to forego in order to enjoy today? In other words, how much is the rider willing to discount his life by assuming that the worst outcome is a tragedy? The concept of hyperbolic discounting might explain the level of discounting utilized by some riders. It suggests that these riders are willing to discount their future at such a high rate that their future becomes less material to them - it is the present which matters the most. Not all riders, however, use hyperbolic discounting. It is most frequently used by those riders who undertake maximum risk (Group B1), or by those riders who can avoid risks but don't (Group A2).

Thus, the specific use that a motorcycle is put to evidences its rider's discount rate - the percentage by which one discounts his or her future. It also determines the rider's opportunity cost incurred, the utility, and also the level of satisfaction derived from the use of the motorcycle. Given the fact that the negatives associated with a motorcycle far outweigh the positives, how rational is it then to ride a motorcycle? Statistics show that motorcycle accidents are on the rise. Why, then, are there more riders taking to the streets on their two-wheeled machines? Riding must have something more profound associated with it, something more than just rationality. It relates to the body and soul - terms all riders associate with. Perhaps there is something in the standard retort most riders will give you:

"Four wheels move the body. Two wheels move the soul." - Author Unknown. 


\section{References}

- Australian Transport Safety Bureau 2008, National Road Safety Action Plan 2007 and 2008, Australian Transport Council, Australian Government, retrieved 2 November 2008, <http://www.atcouncil.gov.au/documents/nrss_actionplan_0708.pdf>

- Brennan, C and Beer, K 2007, Motorcycle safety in Victoria: Black 'spot' the difference, VicRoads, retrieved 2 November 2008, <http://www.roadsafetyconference2007.com.au/Presentation/Brennan_Chri s.pdf>

- Ivancevich, J, Olekalns, M \& Matteson, M 1997, Organisational behaviour and management, first Australian edn, McGraw-Hill, Sydney

- Pirsig, RM 1974, Zen \& the Art of Motorcycle Maintenance, The Bodley Head, London 